\title{
Jejunogastric intussusception prone to misdiagnosis as gastric cancer
}

\author{
Yong-Eun Park ${ }^{1}$, Sang-Woon Kim ${ }^{2}$ \\ ${ }^{1}$ Department of Surgery, Yeungnam University Hospital, Daegu, Korea \\ ${ }^{2}$ Department of Surgery, Yeungnam University College of Medicine, Daegu, Korea
}

Received: January 30, 2020

Revised: March 30, 2020

Accepted: March 31, 2020

Corresponding author:

Yong-Eun Park

Department of Surgery, Yeungnam

University Hospital, 170

Hyeonchung-ro, Nam-gu, Daegu

42415, Korea

Tel: +82-53-620-3580

Fax: +82-53-624-1213

E-mail: cjschddnsrja@gmail.com
The authors report a case of a 78-year-old female with a history of gastric surgery 35 years ago. She was initially misdiagnosed as gastric cancer bleeding and underwent an emergency laparotomy under the diagnosis of jejunogastric intussusception (JGI), 23 hours after the onset of symptoms. We also reviewed $116 \mathrm{JGI}$ case reports and analyzed clinical features and outcomes. Compared to the past, diagnosis of JGI is easier with diagnostic examinations such as an endoscopy, computed tomography, and the upper gastrointestinal series. And a good prognosis can be expected with proper fluid resuscitation and surgical reduction, even if the symptoms persist more than 48 hours.

Keywords: Gastroenterostomy; Intussusception; Jejunogastric intussusception

\section{Introduction}

Jejunogastric intussusception (JGI) occurs in only about $0.1 \%$ of gastro-enteric anastomosis and was first reported by Bozzi in 1914 $[1,2]$. In literature, approximately 300 cases have been reported and the interval from previous gastric surgery to JGI occurrence varies from days to decades $[3,4]$. Unawareness about the disease entity of JGI among clinicians causes an increase in mortality rate due to late diagnosis or misdiagnosis of JGI as gastric malignancy or bezoar. In the present case, we introduce a JGI patient who was misdiagnosed with gastric cancer bleeding and underwent surgical reduction 23 hours after onset of symptoms. We also reviewed previously published JGI case reports that were able to identify basic clinical information. We analyzed the clinical features and outcomes of $116 \mathrm{JGI}$ case reports in the discussion section.

\section{Case}

This study was approved by the Institutional Review Board of
Yeungnam University Hospital (IRB No: 2020-01-004).

A 78-years-old female visited the emergency room of the local hospital due to sudden and continuous epigastric pain from the previous evening. On abdominal computed tomography (CT), gastric distension with intragastric mass was found (Fig. 1) and old bloody drainage through Levin tube was seen. Under diagnosis of gastric cancer bleeding, she was transferred to the emergency room of Yeungnam University Hospital for further evaluation and management.

At the time of arrival, the patient's vital signs were stable and the color of drainage through Levin tube was yellowish. She had medical history of hypertension, diabetes mellitus, pneumonia (1 month back) and surgical history of distal gastrectomy (35 years back).

Physical examination revealed a soft and mild distended abdomen with upper midline scar. There was a palpable mass and mild tenderness on left upper abdomen. There was no rebound tenderness or guarding sign. The laboratory examination showed leukocytosis (white blood cell count, $23.07 \mathrm{~K} / \mu \mathrm{L}$; neutrophil, 93.4\%)

Copyright (C) 2020 Yeungnam University College of Medicine

This is an Open Access article distributed under the terms of the Creative Commons Attribution Non-Commercial License (http://creativecommons.org/licenses/by-nc/4.0/) which permits unrestricted non-commercial use, distribution, and reproduction in any medium, provided the original work is properly cited. 

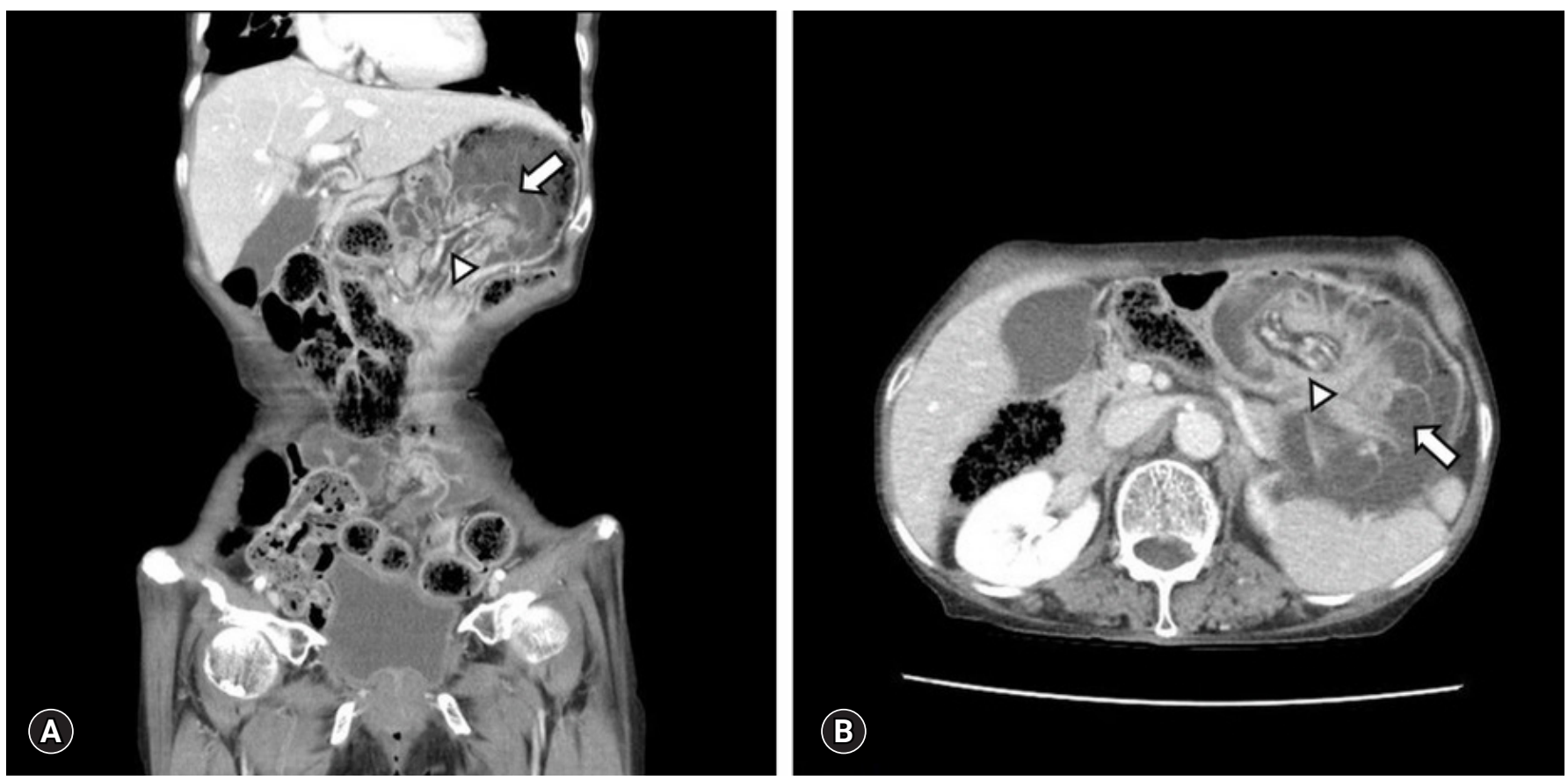

Fig. 1. Computed tomography findings of the jejunogastric intussusception patient. Both coronal (A) and axial view (B) show the intussuscepted jejunal loop (arrow) with the entrapped mesenteric vessel and fat (arrowhead) in the dilated stomach.
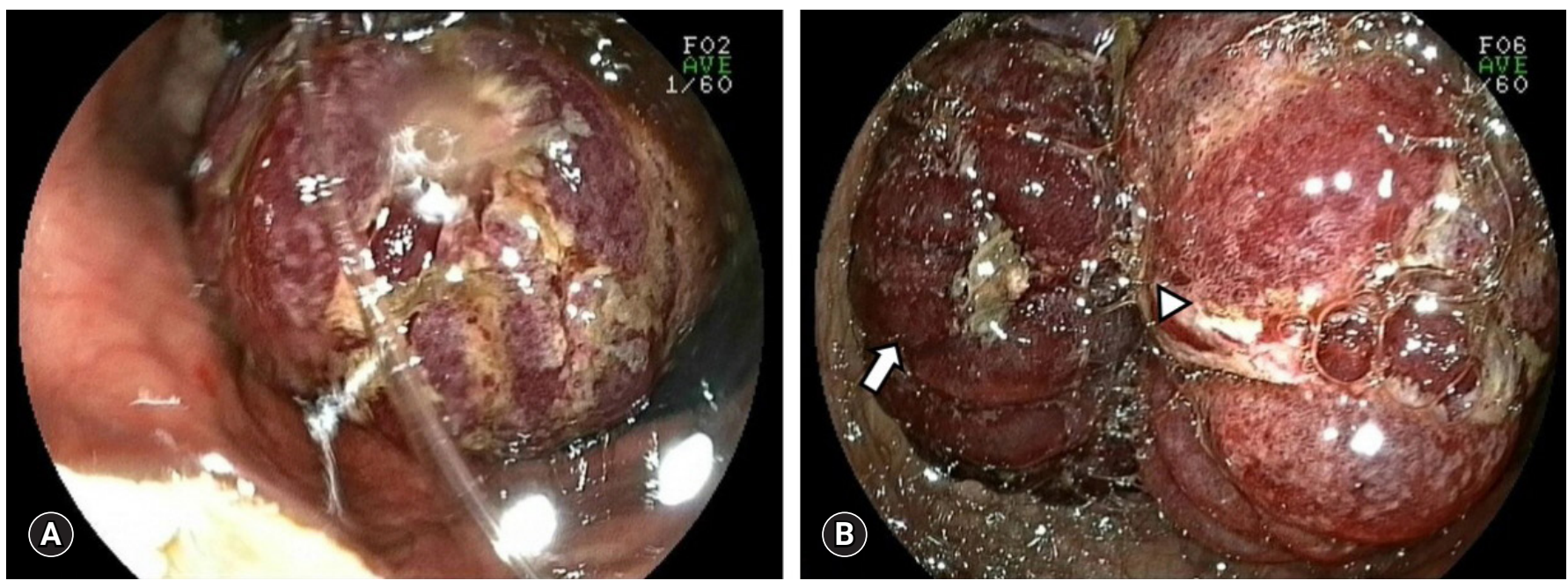

Fig. 2. Endoscopic findings of jejunogastric intussusception patient. (A) A bulky and congestive mass is seen (B) edematous mucosal fold (arrow) and the lumen (arrowhead) of intussuscepted jejunum is seen.

and other findings including hemoglobin within normal range.

The emergency medicine doctor in author's center also misdiagnosed JGI as gastric cancer bleeding and consulted an internal medicine doctor for endoscopy. After 6 hours, internal medicine doctor performed endoscopy and recommended consulting general surgery department for gastric malignancy (Fig. 2). Initially, authors were not aware of the disease entity of JGI. However, continuous abdominal pain and leukocytosis without anemia could not be regarded as mere symptoms of gastric cancer. After reviewing findings of endoscopy and CT, we performed an emergency laparotomy under the diagnosis of JGI.

The afferent loop was dilated and about $60 \mathrm{~cm}$ of efferent loop was intussuscepted into dilated stomach through gastro-jejunostomy site. After manual reduction and warm saline irrigation, there was no leading point and distal half of intussuscepted jejunum was not viable. Segmental resection of necrotic bowel was 
performed. And efferent loop was fixed to distal body of remnant stomach and mesentery of transverse colon to prevent recurrence of JGI. Due to postoperative pneumonia, patient was discharged on the 26th day of surgery.

\section{Discussion}

The mean age of 100 JGI patients was 55 years (range, 27-83 years). There were 68 males (65.4\%) and 36 females (34.6\%). There were 83 cases $(87.4 \%)$ that had a previous surgery for benign disease ( 80 cases of peptic ulcer, three cases of morbid obesity) and 12 cases (12.6\%) had previous surgery for malignant disease (11 cases of gastric cancer, and one case of gall bladder cancer). The mean interval from previous surgery to diagnosis of JGI was $12.4 \pm 10.6$ years (range, 2 days to 55 years; $\mathrm{n}=107)(\mathrm{Ta}$ ble 1). Shackman [5] classified JGI into three types according to the intussuscepted limb, type I (antegrade intussusception of the afferent limb, 16\%), type II (retrograde intussusception of the efferent limb, 74\%), type III (combined form, 10\%). Brynitz and Rubinstein [6] classified JGI into four types by adding type IV (intussusception through Braun's side to side anastomosis). In our results, the percentage of each type was slightly different, but type II was most common type as shown. Among 116 cases, there were five cases (4.3\%) of type I, 98 cases ( $84.5 \%)$ of type II, five cases $(4.3 \%)$ of type III, and eight cases $(6.9 \%)$ of type IV (Table 1). The author's case was type II, which is the most common type ofJGI.

The pathogenesis of JGI remains unclear. But it is thought that mechanical factors and functional factors affect the occurrence of JGI [7]. Functional factors include hyperperistalsis due to hyperacidity or spasm and retrograde peristalsis due to jejunitis or increased abdominal pressure [8]. Mechanical factors include postoperative adhesion, dilatation of bowel following gastrectomy, and long afferent loop or mesentery [9].

There were 100 cases (86.2\%) of JGI with acute symptoms, seven cases (6\%) of JGI with chronic symptoms, and nine cases (7.8\%) of JGI with acute on chronic symptoms. Most JGI shows acute manifestations, but some appear to be chronic and may change to acute if the diagnosis is delayed (Table 1). In the author's case, patient complained of sudden and continuous epigastric pain and physical examination showed a palpable mass on the upper abdomen. Severe colicky epigastric pain, hematemesis, presence of a palpable mass, and vomiting are acute symptoms of JGI [10]. Of the 101 cases that mentioned specific symptoms, there were 89 cases (88.1\%) with abdominal pain, 96 cases (95\%) with vomiting, and 52 cases (51.5\%) with hematemesis. Hematemesis (51.5\%) and palpable mass (34.5\%) were not as common
Table 1. Clinical features of jejunogastric intussusception patients

\begin{tabular}{|c|c|}
\hline Variable & Value \\
\hline Age $(y r, n=100)$ & $55.0 \pm 14.2(27-83)$ \\
\hline \multicolumn{2}{|l|}{$\operatorname{Sex}(n=116)$} \\
\hline Male & $68(65.4)$ \\
\hline Female & $36(34.6)$ \\
\hline N/M & 12 \\
\hline \multicolumn{2}{|l|}{ Type $(n=116)$} \\
\hline I & $5(4.3)$ \\
\hline II & $98(84.5)$ \\
\hline III & $5(4.3)$ \\
\hline IV & $8(6.9)$ \\
\hline \multicolumn{2}{|l|}{ Previous disease $(n=116)$} \\
\hline Benign & $83(87.4)$ \\
\hline Malignant & $12(12.6)$ \\
\hline N/M & 21 \\
\hline Interval $(y r, n=107)$ & $12.4 \pm 10.6$ ( 2 days -55 years) \\
\hline \multicolumn{2}{|l|}{ Symptom ( $n=116)$} \\
\hline Acute & $100(86.2)$ \\
\hline Chronic & $7(6.0)$ \\
\hline Acute on chronic & $9(7.8)$ \\
\hline Duration of acute symptom $(\mathrm{hr}, \mathrm{n}=34)$ & $45.7 \pm 43.4(1-168)$ \\
\hline \multicolumn{2}{|l|}{ Abdominal pain $(n=116)$} \\
\hline Negative & $12(11.9)$ \\
\hline Positive & 89 (88.1) \\
\hline N/M & 15 \\
\hline \multicolumn{2}{|l|}{ Vomiting $(n=116)$} \\
\hline Negative & $5(5.0)$ \\
\hline Positive & $96(95.0)$ \\
\hline N/M & 15 \\
\hline \multicolumn{2}{|l|}{ Hematemesis $(n=116)$} \\
\hline Negative & $49(48.5)$ \\
\hline Positive & $52(51.5)$ \\
\hline $\mathrm{N} / \mathrm{M}$ & 15 \\
\hline \multicolumn{2}{|l|}{ Palpable mass $(n=116)$} \\
\hline Negative & $57(65.5)$ \\
\hline Positive & $30(34.5)$ \\
\hline N/M & 29 \\
\hline \multicolumn{2}{|l|}{ Laboratory findings $(n=116)$} \\
\hline Non-specific & $32(66.7)$ \\
\hline Leukocytosis only & $5(10.4)$ \\
\hline Anemia only & $3(6.3)$ \\
\hline Both & 8 (16.7) \\
\hline N/M & 68 \\
\hline
\end{tabular}

Values are presented as mean \pm standard deviation (range) or number (\%). JGI, jejunogastric intussusception; N/M, not mentioned.

as abdominal pain (88.1\%) and vomiting (95\%) (Table 1). The color of vomit might change from clear to coffee color with the progression of ischemia of intussuscepted limb. If clinicians know 
the disease entity of JGI, it becomes easier to diagnosis JGI with acute symptoms with endoscopy or CT. But if the intussusception of limb is intermittent and self-reversible, patient may complain of vague and chronic symptoms like recurrent bouts of epigastric area and nausea [11]. Diagnosis of JGI with chronic manifestation is difficult and can be performed by timely examination when the symptoms are present [10]. Of the 48 cases that mentioned laboratory findings, there were 32 cases $(66.7 \%)$ with non-specific findings, five cases (10.4\%) with leukocytosis, three cases (6.3\%) with anemia, eight cases (16.7\%) with anemia and leukocytosis (Table 1). Therefore, even if the laboratory finding is within normal limit, the diagnosis of JGI cannot be ruled out.

Endoscopy and abdominal CT are diagnostic examinations of JGI $[12,13]$. During endoscopy, intussuscepted jejunum is visualized. And the nature of intussuscepted jejunum can be various from small intussuscepted jejunum with viable mucosa to bulky congestive mass according to the length of jejunum and degree of ischemia. On the axial and coronal view of CT, intussuscepted jejunal loop with entrapped mesenteric vessel and fat is seen in dilated stomach. Several signs such as claw sign on axial view and target sign on sagittal view are also helpful in the diagnosis of JGI [14]. Of the 79 cases with mention of diagnostic examinations, there were 46 cases (58.2\%) endoscopy, 36 cases (45.6\%) with CT, 26 cases (32.9\%) with upper gastrointestinal (UGI) series, and 12 cases (15.2\%) with ultrasonography. Although UGI series and ultrasonography were not as commonly performed diagnostic test as endoscopy and CT, but they also were useful in diagnosis of JGI. In most JGI cases before 1970, JGI was clinically diagnosed with reference to an abdominal X-ray or UGI series (Table 2).

The treatment of choice for JGI is the surgical reduction of intussuscepted bowel with correction of dehydration and electrolyte disturbance [10]. Also, fixation of intussuscepted limb to adjacent tissues such as parietal wall, transverse colon mesentery, and stomach is required to prevent recurrence of JGI [14]. Authors fixed efferent loop to remnant stomach and transverse colon mesentery. In addition to manual reduction and fixation, bowel resection might be required according to viability of intussuscepted jejunum [15]. There were 82 cases $(85.4 \%)$ with a surgical treatment. Among these cases, 41 cases $(52.6 \%)$ had an additional bowel resection and 22 cases (32.4\%) had fixation to adjacent tissue. There were six cases of recurrence after surgical treatment, of which two cases had a fixation procedure during previous surgery. Therefore, it is hard to say that the fixation can completely prevent the recurrence of JGI (Table 2).

Endoscopic reduction of JGI is a possible option in the treatment of JGI through which general anesthesia and surgical complications such as pneumonia and wound infection can be avoid-
Table 2. Diagnosis, treatment, and outcomes of jejunogastric intussusception patients

\begin{tabular}{|c|c|}
\hline Variable & No. $(\%)$ \\
\hline \multicolumn{2}{|c|}{ Upper gastrointestinal series $(n=116)$} \\
\hline Not done & $53(67.1)$ \\
\hline Done & $26(32.9)$ \\
\hline $\mathrm{N} / \mathrm{M}$ & 37 \\
\hline \multicolumn{2}{|l|}{ Ultrasonography $(n=116)$} \\
\hline Not done & $67(84.8)$ \\
\hline Done & $12(15.2)$ \\
\hline $\mathrm{N} / \mathrm{M}$ & 37 \\
\hline \multicolumn{2}{|l|}{ Endoscopy $(n=116)$} \\
\hline Not done & $33(41.8)$ \\
\hline Done & $46(58.2)$ \\
\hline N/M & 37 \\
\hline \multicolumn{2}{|c|}{ Computed tomography $(n=116)$} \\
\hline Not done & $43(54.4)$ \\
\hline Done & $36(45.6)$ \\
\hline $\mathrm{N} / \mathrm{M}$ & 37 \\
\hline \multicolumn{2}{|l|}{ Treatment method $(n=116)$} \\
\hline Spontaneous reduction & $3(3.1)$ \\
\hline Surgical reduction & $80(83.3)$ \\
\hline Endoscopic reduction & $6(6.3)$ \\
\hline Surgery after endoscopy & $2(2.1)$ \\
\hline No reduction & $5(5.2)$ \\
\hline $\mathrm{N} / \mathrm{M}$ & 20 \\
\hline \multicolumn{2}{|l|}{ Bowel resection $(n=82)^{a)}$} \\
\hline Not done & $37(47.4)$ \\
\hline Done & $41(52.6)$ \\
\hline $\mathrm{N} / \mathrm{M}$ & 4 \\
\hline \multicolumn{2}{|l|}{ Fixation $(n=82)^{a)}$} \\
\hline Not done & $46(67.6)$ \\
\hline Done & $22(32.4)$ \\
\hline $\mathrm{N} / \mathrm{M}$ & 14 \\
\hline \multicolumn{2}{|l|}{ Recurrence $(n=108)^{b)}$} \\
\hline Negative & $80(90.9)$ \\
\hline Positive & $8(9.1)$ \\
\hline N/M & 20 \\
\hline \multicolumn{2}{|l|}{ Prognosis $(n=116)$} \\
\hline Well recovered & $88(91.7)$ \\
\hline Died & $8(8.3)$ \\
\hline $\mathrm{N} / \mathrm{M}$ & 20 \\
\hline
\end{tabular}

$\mathrm{N} / \mathrm{M}$, not mentioned.

${ }^{a)}$ Number of cases with surgical reduction. ${ }^{\text {b) }}$ Number of death cases excluded.

ed [16]. Nevertheless, endoscopic reduction of JGI has a significant risk of recurrence and should not be performed in situation where bowel ischemia or peritoneal irritation sign is suspected [17]. There were six cases (6.3\%) of endoscopic reduction, of 


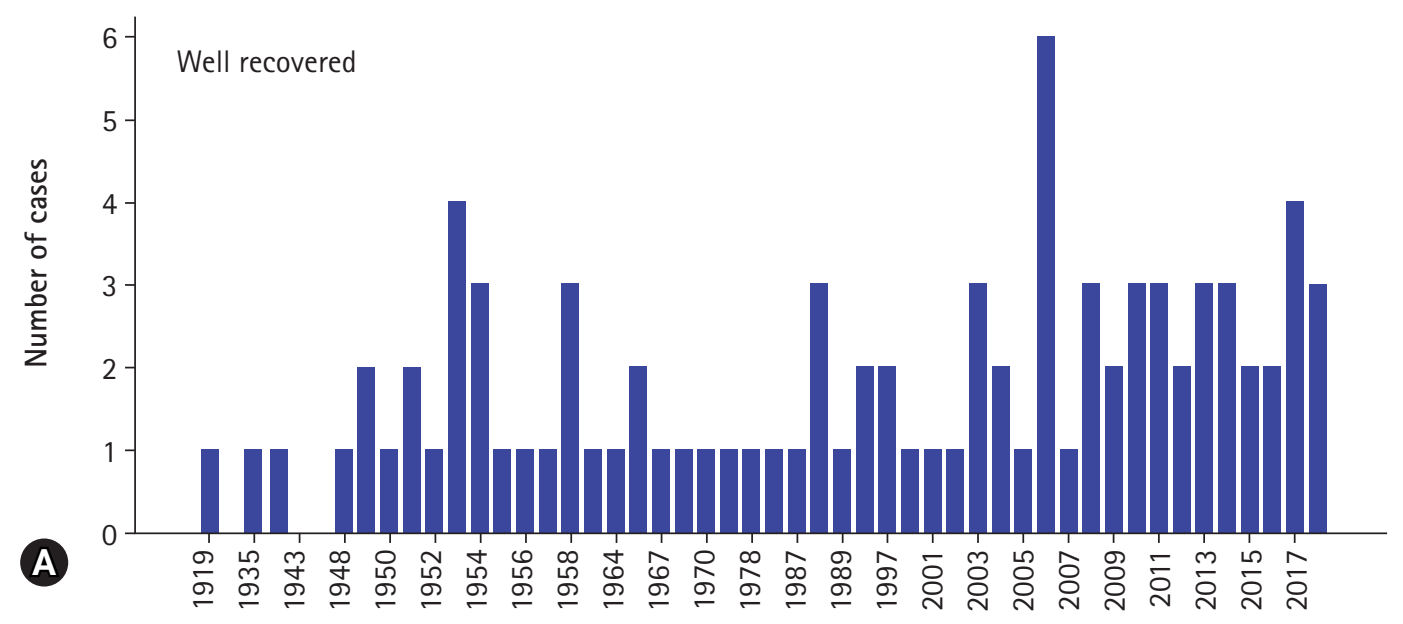

Published year

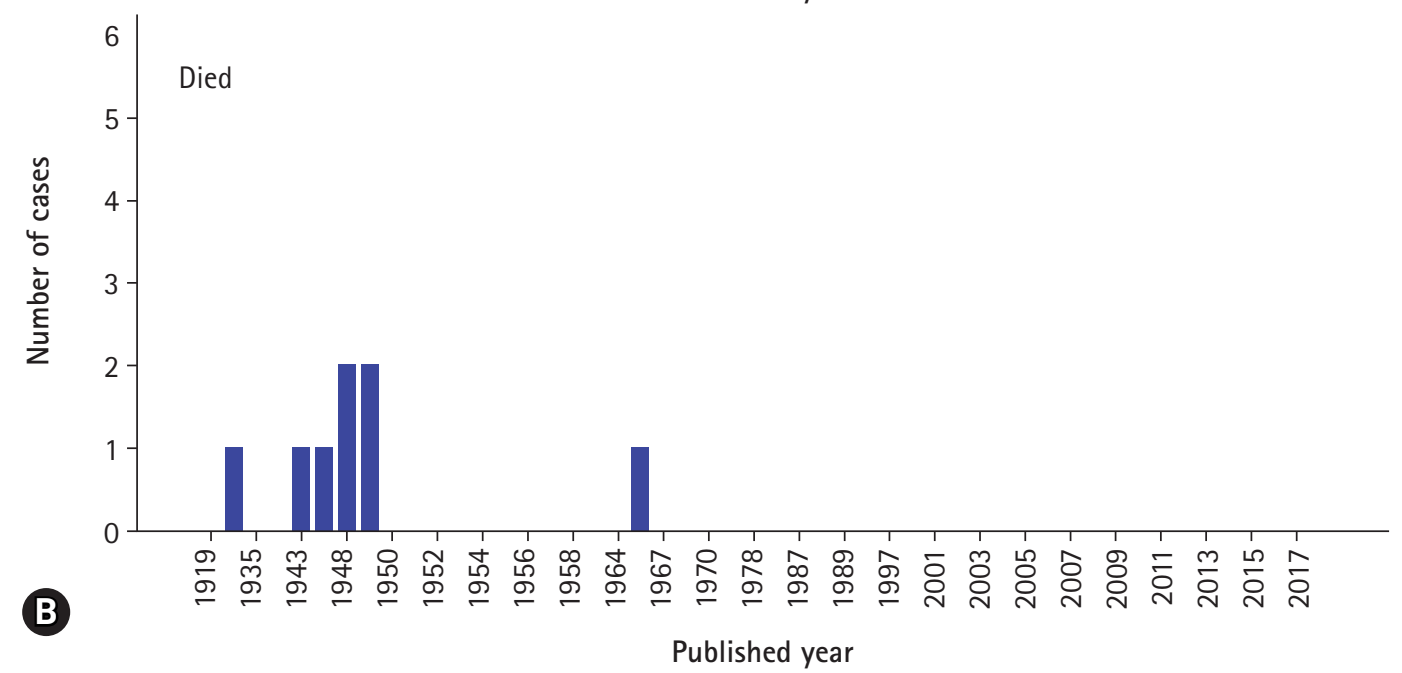

Fig. 3. Numbers of well recovered (A) and died (B) jejunogastric intussusception cases are demonstrated by published year.

which two cases recurred. The recurrence rate of an endoscopic reduction ( 2 out of $6,33.3 \%$ ) was higher than the recurrence rate of a surgical reduction ( 6 out of $82,7.3 \%$ ) (Table 2 ).

In this case, due to initial misdiagnosis, the surgical reduction was performed 23 hours after occurrence of sudden epigastric pain. It has been reported that if surgical treatment is performed within first 48 hours, the mortality rate of JGI patient can be about $10 \%$, if not, may increase over 50\% [18]. In our results, only 34 out of 100 acute JGI cases mentioned the duration of the symptoms. The mean duration of acute symptom was $45.7 \pm 43.4$ hours and ranged 1 hour to 7 days (Table 1 ). The mortality rate was $8.3 \%$ ( 8 out of 96 ) and all mortality cases were reported before 1970s. Interestingly, all JGI case reports after 1970 had endoscopic or surgical reduction and had good prognosis regardless of the duration of the symptoms (Table 2, Fig. 3).

If clinicians are aware of the disease entity of JGI, JGI is easily diagnosed by various examinations such as endoscopy, CT, and the UGI series. And a good prognosis can be expected even if the symptoms persist more than 48 hours, provided adequate fluid resuscitation and surgical reduction are performed.

\section{Acknowledgments}

\section{Conflicts of interest}

No potential conflict of interest relevant to this article was reported.

\section{Author contributions}

Conceptualization: YEP, SWK; Data curation, Formal analysis: YEP, SWK; Writing-original draft, Writing-review \& editing: YEP. 


\section{ORCID}

Yong-Eun Park, https://orcid.org/0000-0001-6882-2973

Sang-Woon Kim, https://orcid.org/0000-0003-1522-1685

\section{References}

1. Lee SH, Kwon IG, Ryu SW, Sohn SS. Jejunogastric intussusception: a rare complication of gastric cancer surgery. Int J Clin Exp Med 2014;7:4498-502.

2. WISOFF CP. Jejunogastric intussusception. Radiology 1953;61:363-7.

3. Kawano F, Tashiro K, Nakao H, Fujii Y, Ikeda T, Takeno S, et al. Jejunogastric intussusception after distal gastrectomy with Roux-en-Y reconstruction: a case report. Int J Surg Case Rep 2018;44:105-9.

4. Tokue H, Tsushima Y, Arai Y, Endo K. Jejunogastric intussusception: life-threatening complication occuring 55 years after gastrojejunostomy. Intern Med 2009;48:1657-60.

5. Shackman R. Jejunogastric intussusception. Br J Surg 1940; 27:475-80.

6. Brynitz S, Rubinstein E. Hematemesis caused by jejunogastric intussusception. Endoscopy 1986;18:162-4.

7. Kitasato Y, Midorikawa R, Uchino Y, Saku S, Minami T, Shirahama $T$, et al. A case of retrograde intussusception at Roux-en-Y anastomosis 10 years after total gastrectomy: review of the literature. Surg Case Rep 2016;2:123.

8. Hocking MP, McCoy DM, Vogel SB, Kaude JV, Sninsky CA. Antiperistaltic and isoperistaltic intussusception associated with abnormal motility after Roux-en-Y gastric bypass: a case report. Surgery 1991;110:109-12.
9. Bundrick TJ, Turner MA. Retrograde jejunogastric intussusception. Rev Interam Radiol 1981;6:21-4.

10. Sachdev BS, Malhotra P, Sukanya B, Prasad L, Kapoor D. Post gastro-jejunostomy acute retrograde jejuno-gastric intussusception. Trop Gastroenterol 2010;31:329-32.

11. Reyelt WP Jr, Anderson AA. retrograde jejunogastric intussusception. Surg Gynecol Obstet 1964;119:1305-11.

12. Czerniak A, Bass A, Bat L, Shemesh E, Avigad I, Wolfstein I. Jejunogastric intussusception. A new diagnostic test. Arch Surg 1987;122:1190-2.

13. Hashimoto Y, Akagi S, Sakashita Y, Takamura M, Iwako H, Watadani $Y$, et al. Usefulness of computed tomography as a preoperative diagnostic modality in a case with acute jejunogastric intussusception. J Gastrointest Surg 2007;11:1078-80.

14. Singh S, Singh A, Bhagat S, Singh B. Retrograde Jejuno-gastric Intussusception. Niger J Surg 2015;21:70-2.

15. Rather SA, Dar TI, Wani RA, Khan A. Jejunogastric intussusception presenting as tumor bleed. J Emerg Trauma Shock 2010;3:406-8.

16. Toth E, Arvidsson S, Thorlacius H. Endoscopic reduction of a jejunogastric intussusception. Endoscopy 2011;43(Suppl 2 UCTN):E63.

17. Guadagni S, Pistoia M, Catarci M, Carboni F, Lombardi L, Carboni M. Retrograde jejunogastric intussusception: is endoscopic or surgical management more appropriate? Surg Today 1992;22:269-72.

18. Walstad PM, Ritter JA, Arroz V. Delayed jejunogastric intussusception after gastric surgery: an ever-present threat. Am Surg 1972;38:172-5. 